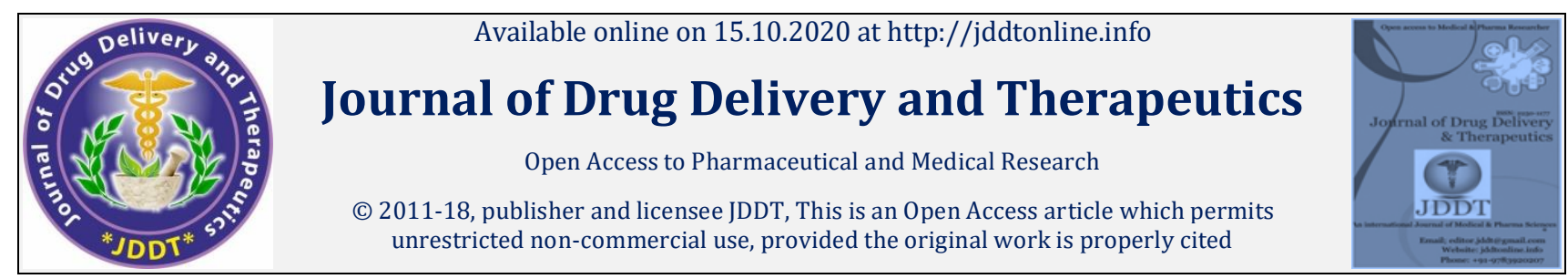

Open Access

Research Article

\title{
Phytochemical and Pharmacological Investigations of Lannea grandis (Dennst.) Engl. Leaves Extracts
}

\author{
Sharmin Akhter ${ }^{1}$, Sarrin Shahadat' ${ }^{1}$ Zilly Homa ${ }^{1}$, Md. Ruhul Kuddus², M Mohi Uddin Chowdhury¹, \\ Mohammed Ibrahim ${ }^{*}$ \\ ${ }^{1}$ Department of Pharmacy, Southern University Bangladesh, Chittagong, Bangladesh \\ 2 Department of Pharmaceutical Chemistry, Faculty of Pharmacy, University of Dhaka, Dhaka-1000, Bangladesh
}

\begin{abstract}
Medicinal plants can serve as a prominent source of bioactive secondary metabolites which can exert beneficial effects to combat against many human diseases. Lannea grandis (Dennst.) Engl, a member of Anacardiaceae family has several applications in the ethnomedical practices. In this study, the ethanol extract of L. grandis leaf (ELG) along with its petroleum-ether and chloroform fractions were subjected to phytochemical analysis along with the evaluation of antimicrobial, anti-diarrheal, and sedative activities using standard protocols. Phytochemical screening was performed according to common phytochemical tests. Antimicrobial assay was carried out by disc diffusion method where the ethanol extract of $L$. grandis showed significant activity against tested bacterial species (zone of inhibitions $=10.8 \pm 0.85$ to $13.8 \pm 1.84 \mathrm{~mm}$ ). The same extract also exhibited the highest antifungal activity against Blastomyces dermatitidis (zone of inhibition $=20.5 \pm 0.35 \mathrm{~mm}$ ). The chloroform fraction of $L$. grandis at the dose of $400 \mathrm{mg} / \mathrm{kg}$ body weight produced a significant $(\mathrm{p}<0.05)$ anti-diarrheal effect with $40.69 \%$ inhibition of castor oil-induced diarrhea in mice. During sedative activity assay in mice, the plant extract at the dose of $400 \mathrm{mg} / \mathrm{kg}$ body weight produced mild reduction in the time of onset of sleep and increased the length of the sleeping time induced by a sedative, phenobarbitone. In conclusion, the plant $L$. grandis can be considered as a base for the development of new drugs and phytomedicine.
\end{abstract}

Keywords: Lannea grandis, phytochemical, antimicrobial, anti-diarrheal, sedative activity.

Article Info: Received 11 Aug 2020; Review Completed 14 Sep 2020; $\quad$ Accepted 26 Sep 2020; Available online 15 Oct 2020

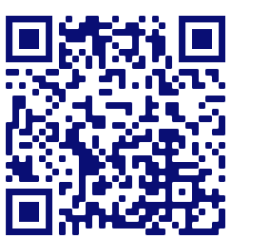

Cite this article as:

Akhter S, Shahadat S, Homa Z, Kuddus MR, Chowdhury MMU, Ibrahim M, Phytochemical and Pharmacological Investigations of Lannea grandis (Dennst.) Engl. Leaves Extracts, Journal of Drug Delivery and Therapeutics. 2020; 10(5-s):85-89 http://dx.doi.org/10.22270/jddt.v10i5-s.4431

Dr Mohammed Ibrahim, Department of Pharmacy, Southern University Bangladesh, Chittagong, Bangladesh

\section{INTRODUCTION}

Since the time immemorial, people have been using herbal remedies and medicines to cure various diseases 1,2 . The interest in drugs of plant origin is still increasing because plants are the valuable source of structurally diverse compounds, which possess therapeutic potential for treatment of human diseases ${ }^{2}$. A lot of the clinically used therapeutic agents are of natural products origin. Thus, natural products have been well recognized and documented as a source of inspiration to drug discovery 3,4 . Traditional medical practice is still the main vehicle of health care delivery today especially in the rural areas of the country where conventional medical facilities are not within the reach of most people 5 . Increase in the patronage of herbal medicines is likely to carry on because of the global economic recession. Moreover, a large proportion of the world population rely on herbal medicines for their medical care $^{6}$.
Lannea grandis (Dennst.) Engl. (Family: Anacardiaceae), Synonym- Lannea coromandelica (Houtt.) Merr is a mediumsized deciduous tree which grows up to 10 to $20 \mathrm{~m}$ in height. The plant is widely distributed in Bangladesh, India and some other tropical countries ${ }^{7}$. Locally it is common as Bhadi, and is cultivated as a hedge plant in the roadside areas. The folk people in Bangladesh used the plant for various diseases including pain, inflammation and infection ${ }^{8}$. The leaf of the plant is reported to be useful in scurvy, skin diseases, dysentery, and pain. Leaves and barks were reported to have astringent properties and applied in toothache9. The ethanol bark extract of $L$. coromandelica exhibited significant pain relieving activity in mice model 10 . In an earlier report, polyflavonoid tannins were isolated from the stem bark of $L$. coromandelica which showed sporocidal activity ${ }^{11}$.

Although the plant L. grandis is traditionally very important, but the scientific reports regarding its pharmacological studies are inadequate. Therefore, as a continuation of our 
research on medicinal plants,12-14 the present study was designed to identify the phytochemicals as well as to determine the level of antimicrobial, anti-diarrheal, and sedative activity of leaves of Lannea grandis Engl.

\section{MATERIALS AND METHODS}

\section{Collection and identification of plant material}

Leaves of L. grandis were collected from the hill of Forest Research Institute, Chittagong, Bangladesh and were identified by Forest Research Institute, Chittagong, Bangladesh.

\section{Extraction}

The leaves were first air-dried followed by oven drying at $35^{\circ} \mathrm{C}$ and ground to coarse powder with a grinder. About 250 $\mathrm{g}$ of powdered sample was taken in an amber bottle and extracted with $97.7 \%$ ethanol for 7 days. Meanwhile another $150 \mathrm{~g}$ of same plant powder was subjected to hot extraction with $97.7 \%$ ethanol using Soxhlet apparatus ${ }^{15}$. The extract was filtered through a cotton plug followed by Whatman filter paper no.1. The volume of the filtrate was condensed at reduced temperature and pressure to obtain a gummy concentrate which is designated as ethanol extract of $L$. grandis (ELG). The resulting crude extract obtained by both cold and hot extraction was mixed together and was subjected to fractionation with petroleum-ether and chloroform subsequently to obtain petroleum-ether (PEF) and chloroform (CFF) soluble fractions, respectively. The amount of the ELG, PEF and CFF were $7.13 \mathrm{~g}, 4.56 \mathrm{~g}$ and 3.02 g, respectively.

\section{Phytochemical screening}

The ethanol crude extract of L. grandis and its petroleumether and chloroform fractions were examined by qualitative tests for the existence of the phytochemical constituents by using the standard methods ${ }^{16,17}$ as mentioned in Table 1.

\section{Antimicrobial activity}

The antimicrobial susceptibility of L. grandis was initially evaluated by the agar disc diffusion assay ${ }^{18}$ using a variety of test microorganisms (Table 2). Ciprofloxacin and fluconazole were used as standards. The organisms were obtained as pure culture from the Faculty of Biology, University of Chittagong, Bangladesh. The antimicrobial activity of the test agents was determined by measuring the diameter of zone of inhibition expressed in $\mathrm{mm}$. The experiments were carried out in triplicate and the results have been shown as mean \pm SD (Table 2).

\section{Determination of minimum inhibitory concentration (MIC)}

The minimum inhibitory concentration (MIC) of the plant samples that revealed a good activity in disc diffusion assay were subjected to determine the MIC value by the serial tube dilution technique ${ }^{19}$ in broth medium, containing graded concentration of the plant extracts inoculated with the test organisms.

\section{Test animals}

Swiss Albino mice of either sex (aged 4-5 weeks) weighing 25-30 g were collected from the Animal Resources Branch of the International Centre for Diarrheal Diseases and Research, Bangladesh (icddr,b). They were kept in standard laboratory conditions at room temperature $\left(24 \pm 2^{\circ} \mathrm{C}\right)$ and relative humidity (60-70\%) in a $12 \mathrm{~h}$ light/12 h dark cycle. All the experiments were conducted according to the protocol 20 approved by the institutional ethical committee.

\section{Anti-diarrheal activity}

The anti-diarrheal activity of L. grandis was evaluated by castor oil-induced diarrhea model in mice ${ }^{21}$. The experimental animals were arbitrarily divided into five groups having five mice in each. Negative control group received vehicle (1\% Tween-80 in water) at a dose of 10 $\mathrm{ml} / \mathrm{kg}$ whereas the standard group received loperamide at a dose of $3 \mathrm{mg} / \mathrm{kg}$ as oral suspension. Test groups received plant extracts (ELG, PEF and CFF) at the dose of $400 \mathrm{mg} / \mathrm{kg}$ orally. Thirty min later diarrhea was induced by oral administration of $0.4 \mathrm{ml}$ castor oil to each mouse. During the observation period $(4 \mathrm{~h})$, the total latency period and the number of diarrheic feces excreted by the animals were recorded.

\section{Sedative activity}

The sedative activity of $L$. grandis was assessed by phenobarbitone sleeping time test in mice 22 . The test animals were randomly divided into five groups as mentioned above. The positive control group was given standard diazepam (1 $\mathrm{mg} / \mathrm{kg}$, i.p.) while the test groups received plant samples (ELG, PEF and CFF) orally at a dose of $400 \mathrm{mg} / \mathrm{kg}$ body weight. After $30 \mathrm{~min}$ of administration of test drugs, phenobarbitone at a dose of $40 \mathrm{mg} / \mathrm{kg}$ body weight was administered by intra-peritoneal route to all groups of mice to measure phenobarbitone induced sleeping time. The animals were observed for the latent period (time between phenobarbitone administration to loss of righting reflex) and duration of sleep (time between the loss and recovery of righting reflex).

\section{Statistical analysis}

Data were expressed as mean \pm SD (standard deviation) and mean \pm SEM (standard error of mean). The results were considered statistically significant when $\mathrm{p}<0.05$.

\section{RESULTS AND DISCUSSION}

The preliminary phytochemical screening study revealed that the crude ethanol extract, petroleum-ether fraction and chloroform fraction of L. grandis were rich of some vital chemical groups like alkaloids, steroids, tannins, saponins, glycosides and gummy types plants secondary metabolites (Table 1) which are responsible for exposing different types of pharmacological activity23. 
Table 1: Phytochemicals present in the ELG, PEF and CFF of L. grandis.

\begin{tabular}{|c|c|c|c|c|}
\hline \multirow{2}{*}{ Examination } & \multirow{2}{*}{ Name of the test } & \multicolumn{3}{|c|}{ Plant sample } \\
\hline & & ELG & PEF & CFF \\
\hline \multirow{2}{*}{ Reducing sugar } & Fehling's solution test & + & - & - \\
\hline & Benedict's test & + & + & + \\
\hline Steroids & Salkowski \& Libermann-burchared test & + & - & - \\
\hline \multirow[t]{2}{*}{ Glycosides } & Salkowski \& Libermann-burchared test & - & - & - \\
\hline & Potassium dichromate test & + & - & + \\
\hline \multirow[t]{4}{*}{ Tannins } & Keller-Kiliani test & - & - & + \\
\hline & Ferric chloride Test & + & - & - \\
\hline & Mayer's test & + & + & - \\
\hline & Dragendorff's reagent test & + & - & - \\
\hline \multirow[t]{3}{*}{ Alkaloids } & Wagner's reagent test & + & - & - \\
\hline & Hager's reagent test & - & - & - \\
\hline & Tannic acid test & - & - & - \\
\hline Flavonoids & -- & - & - & - \\
\hline Saponins & -- & + & - & + \\
\hline Gums & -- & - & - & + \\
\hline Amides & -- & - & - & - \\
\hline
\end{tabular}

[+ = presence; - = absent. ELG=Ethanol crude extract of $L$. grandis leaf, PEF =Petroleum ether fraction,

$\mathrm{CFF}=$ Chloroform fraction of L. grandis]

The demand for novel antimicrobial agents from natural sources is mounting day by day ${ }^{24}$. In order to find out the prospective antimicrobial principles, the plant L. grandis was subjected for preliminary antimicrobial screening by disc diffusion method. During antimicrobial test, the plant samples showed mild to moderate activity against tested organisms (Table 2). The ethanol extract showed antibacterial activity with zone of inhibition ranging from
$10.8 \pm 0.85$ to $13.8 \pm 1.84 \mathrm{~mm}$. The maximum antibacterial potential was observed by ethanol extract of $L$. grandis against $S$. aureus $(13.8 \pm 1.31 \mathrm{~mm})$ and $E$. coli $(13.8 \pm 1.84)$. The petroleum-ether fraction exhibited no activity against any test microorganisms while the chloroform fraction showed activity against Shigella dysenteriae $(10.7 \pm 0.47)$ and Escherichia coli $(11.83 \pm 1.03)$.

Table 2: Antimicrobial activity of different extract of L. grandis, ciprofloxacin and fluconazole:

\begin{tabular}{lccc}
\hline \multirow{2}{*}{ Test organisms } & \multicolumn{3}{c}{ Zone of inhibition (MZI \pm SD) $\mathrm{mm}$} \\
\cline { 2 - 4 } & ELG & CFF & Standard \\
\hline Gram positive bacteria & $13 \pm 1.63$ & nd & $28.2 \pm 0.85$ \\
Bacillus subtilis & $13.8 \pm 1.31$ & nd & $28.5 \pm 1.087$ \\
Staphylococcus aureus & & & \\
Gram negative bacteria & $13.8 \pm 1.84$ & $11.83 \pm 1.03$ & $30.2 \pm 1.43$ \\
Escherichia coli & $12 \pm 1.63$ & nd & $30.7 \pm 2.57$ \\
Salmonella Typhi & $10.8 \pm 0.85$ & $10.7 \pm 0.47$ & $29.2 \pm 1.85$ \\
Shigella dysenteriae & $10.8 \pm 1.03$ & nd & $30.2 \pm 0.62$ \\
S. sonnei & $12.5 \pm 1.5$ & nd & $27.7 \pm 2.1$ \\
Vibrio cholerae & & & Fluconazole \\
Fungi & $20.5 \pm 0.35$ & $13.3 \pm 1.08$ & $23.5 \pm 0.94$ \\
Blastomyces dermatitidis & nd & $11.3 \pm 1.47$ & $25.5 \pm 0.54$ \\
Candida albicans & $13.7 \pm 1.34$ & nd & $23 \pm 2.16$ \\
Cryptococcus neoformans & $13.2 \pm 1.14$ & nd & $25.3 \pm 1.78$ \\
Microsporum spp. &
\end{tabular}

*[nd: Not detected; MZI: Mean zone of inhibition (mm); SD = Standard deviation; Zone of inhibition under $8 \mathrm{~mm}$ was considered as less active and was discarded ] 
In case of antifungal screening, the ethanol extract of $L$. grandis showed strong antifungal activity against $B$. dermatitidis (zone of inhibition $=20.5 \pm 0.35 \mathrm{~mm}$ ) while the chloroform fraction revealed moderate activity against $B$. dermatitidis (zone of inhibition $=13.3 \pm 1.08 \mathrm{~mm}$ ) and $C$. albicans (zone of inhibition $=11.3 \pm 1.47 \mathrm{~mm}$ ). During the MIC determination, the extracts displayed low MIC value of
$15.625 \mu \mathrm{g} / \mathrm{ml}$ against $B$. dermatitidis. This result suggested the presence of antimicrobial compounds in the extractives. The manifestation of antimicrobial activity of L. grandis against both bacteria and fungi may be considered as a good source of bioactive compounds having antimicrobial properties 25 .

Table 3: Anti-diarrheal effect of L. grandis extractives in mice

\begin{tabular}{lccccc}
\hline Treatment & MLP (h) & \%MLP & TLP & $\begin{array}{c}\text { \% Inhibition of } \\
\text { defecation }\end{array}$ & $\begin{array}{c}\text { TNF } \\
(240 \mathrm{~min})\end{array}$ \\
\hline Control (1\% Tween 80) & 0.81 & 100.0 & $4.05 \pm 6.36$ & 0 & $86 \pm 3.049$ \\
Loperamide 3 mg/kg & 1.40 & 172.84 & $7.00 \pm 7.17^{\mathrm{a}}$ & 62.79 & $32 \pm 1.48^{\mathrm{a}}$ \\
ELG 400 mg/kg & 1.07 & 132.09 & $5.35 \pm 3.82^{\mathrm{b}}$ & 5.81 & $81 \pm 2.33^{\mathrm{a}}$ \\
PEF 400 mg/kg & 0.94 & 116.05 & $4.70 \pm 6.17^{\mathrm{a}}$ & 19.77 & $69 \pm 2.72^{\mathrm{b}}$ \\
CFF 400 mg/kg & 0.87 & 107.41 & $4.35 \pm 4.22^{\mathrm{a}}$ & 40.69 & $51 \pm 2.08^{\mathrm{a}}$ \\
\hline
\end{tabular}

$*[$ ap $<0.05$, b $\mathrm{p}<0.1 ; \%$ MLP $=($ test group MLP $\times 100) /$ Control MLP; TLP = Total latent period $(\mathrm{MLP} \times 5 \pm \mathrm{SEM}) ; \mathrm{TNF}=$

Total number of feces $(\mathrm{MD} \times 5 \pm \mathrm{SEM})]$

Medicinal plants are gifted source of new anti-diarrheal drugs. There are a huge number of plant-based medicines that are reported to be helpful in treating diarrhea. Therefore, to find out a new anti-diarrheal agent from plant source, L. grandis was investigated for the evaluation of antidiarrheal activity by castor oil-induced diarrhea in mice. Ricinoleic acid, the principal ingredient of castor oil is reported to bring out enhanced peristaltic movement and finally induces diarrhea ${ }^{26}$. In the castor oil induced diarrheal test, the different extracts of the L. grandis at the doses of $400 \mathrm{mg} / \mathrm{kg}$ reduced the total number of diarrheal feces as well as increased the latency period in mice to a considerable extent and these effects are comparable to the control groups (Table 3). The chloroform fraction of $L$. grandis reduced the diarrheal episode by $40.69 \%$ inhibition. The standard loperamide produced $62.79 \%$ inhibition of diarrhea in mice. The ethanol extract, petroleum ether and chloroform fraction reduced the total number of feces to $81 \pm 2.33,69 \pm 2.72$ and $51 \pm 2.08$, respectively. And the total latent periods were $5.35 \pm 3.82,4.70 \pm 6.17,4.35 \pm 4.22 \mathrm{~h}$ respectively compared to the positive control $(7.00 \pm 7.17 \mathrm{~h})$ respectively. From the above experiment it should be claimed that the plant was found to be effective in the management of diarrhea. The anti-diarrheal effect of $L$. grandis might be caused by the bioactive phytoconstituents present in the test sample, however further studies are required ${ }^{27}$.

Table 4: Sedative activity of L. grandis extractives in mice.

\begin{tabular}{lcc}
\hline \multicolumn{1}{c}{ Treatment } & TLP (min) & TST (min) \\
\hline Diazepam $1 \mathrm{mg} / \mathrm{kg}$ & $43 \pm 1.61^{\mathrm{a}}$ & $235 \pm 3.04^{\mathrm{b}}$ \\
ELG $400 \mathrm{mg} / \mathrm{kg}$ & $141 \pm 3.65^{\mathrm{a}}$ & $123 \pm 3.46^{\mathrm{a}}$ \\
PEF $400 \mathrm{mg} / \mathrm{kg}$ & $82 \pm 2.23^{\mathrm{a}}$ & $84 \pm 3.03^{\mathrm{a}}$ \\
CFF $400 \mathrm{mg} / \mathrm{kg}$ & $104 \pm 3.05^{\mathrm{a}}$ & $61 \pm 2.03^{\mathrm{a}}$
\end{tabular}

[* ap $<0.01$, bp $<0.05$, cp $<0.1 ;$ TLP(Total latent period): $($ mean $\times 5) \pm$ SEM; TST $($ Total sleeping time $):($ mean $\times 5) \pm$ SEM; SEM = Standard Error of Mean]

The test samples $(400 \mathrm{mg} / \mathrm{kg}$ body weight) moderately reduced the latency period as well as prolonged the phenobarbitone-induced sleeping time, with respect to the control (Table 4). These findings revealed that the plant samples may have sleep inducing properties. The prolongation of sleeping time is probably through a CNS depressant action or a sedative action ${ }^{28}$ of the test samples.

\section{CONCLUSION}

From these studies it was found that the crude extracts of the plant L. grandis contained important chemical groups like alkaloids, steroids, tannins, saponins, glycosides and gummy types. The plant also possesses significant antimicrobial, anti-diarrheal and sedative activity when compared with corresponding standard drugs. So, advance research is imperative to discover the bioactive principles and exact mechanisms of action.

\section{ACKNOWLEDGEMENT}

The authors would like to acknowledge the Forest Research Institute, Chittagong, Bangladesh for plant identification.

\section{CONFLICT OF INTEREST}

No competing interests.

\section{REFERENCES}

1. Cragg GM, Newman DJ. Natural products: a continuing source of novel drug leads. Biochimica et Biophysica Acta 2013; 1830:3670-3695.

2. Martins E. The growing use of herbal medicines: issues relating to adverse reactions and challenges in monitoring safety. Frontiers in Pharmacology 2014; 4:1-10.

3. Cragg GM, Newman DJ. Natural product drug discovery in the next millennium. Pharmaceutical Biology 2001; 39 Suppl 1:817.

4. Cragg GM, Newman DJ. Discovery and development of antineoplastic agents from natural sources. Cancer Investigation 1999; 17(2):153-163.

5. Mukherjee PW. Quality Control of Herbal Drugs: An Approach to Evaluation of Botanicals. New Delhi, India: Business Horizons Publishers, 2002.

6. Ekor M. The growing use of herbal medicines: issues relating to adverse reactions and challenges in monitoring safety. Frontiers in Pharmacology 2014; 4:177.

7. Islam MT, Tahara S. Dihydroflavonols from Lannea coromandelica. Phytochemistry 2000; 54(8):901-907. 
8. Yusuf M, Chowdhury JU, Wahab MA, Begum J. Medicinal plants of Bangladesh. Bangladesh Council of Scientific \& Industrial Research (BCSIR), Dhaka, Bangladesh, 1994; p. 1-340.

9. Kirtikar KR, Basu BD. Indian medicinal plants. 2nd ed. Bishen Singh-Mahendrapal Singh, India 1975; 664-666.

10. Rahman M, Khatun A, Uddin S, Shilpi JA. Comparative effect of Lannea coromandelica (Houtt.) Merr. leaves and stem barks on acetic acid induced pain model in mice and chromagenic reagents:exploring the analgesic potential and phytochemical groups. Pharmacologyonline 2016; 1(1):146-152.

11. Islam MT, Ito $\mathrm{T}$, Sakasai M, et al. Zoosporicidal activity of polyflavonoid tannin identified in Lannea coromandelica stem bark against phytopathogenic oomycete Aphanomyces cochlioides. The Journal of Agricultural and Food Chemistry 2002; 50:6697-6703.

12. Islam M, Jannat T, Kuddus MD, Rashid MA, Haque, MR. In vitro and in vivo evaluation of pharmacological potentials of Campsis radicans L. Clinical Phytoscience 2019; 5:42.

13. Arif M, Kuddus MR, Islam MT, Ibrahim M. Evaluation of In vivo and In vitro biological activities of Gardenia latifolia Ait leaf GSC Biological and Pharmaceutical Sciences 2019; 7(03):116123.

14. Moniruzzaman M, Kuddus MR, Chowdhury AMS and Rashid MA. Antioxidant, antimicrobial, anti-diarrheal and analgesic activities of Diospyros malabarica (Desr.) Kostel. Bangladesh Pharmaceutical Journal 2019; 22(1):27-33.

15. Azwanida NN. A Review on the Extraction Methods Used in Medicinal Plants, Principle, Strength and Limitation. Medicinal \& Aromatic Plants 2015; 4:196.

16. Ghani A. Medicinal Plants of Bangladesh. $2^{\text {nd }}$ ed. Bangladesh: The Asiatic Society of Bangladesh; 2003. p. 31. 39-40, 418, 500-504.

17. Trease GE and Evans WC. Phenols and phenolic glycosides, in Textbook of Pharmacognosy, vol. 12, p. 343-383, Balliese, Tindall and Co Publishers, London, UK, 1989.

18. Bauer AW, Kirby WM, Sherris JC, Turck M. Antibiotic susceptibility testing by a standardized single disk method. American Journal of Clinical Pathology 1966; 45(4):493-496.

19. Bussmann RW, Malca-García G, Glenn A, et al. Minimum inhibitory concentrations of medicinal plants used in Northern Peru as antibacterial remedies. Journal of Ethnopharmacology 2010; 132(1):101-108.

20. Zimmermann M. Ethical guidelines for investigations of experimental pain in conscious animals. Pain 1983; 16:109110

21. Shoba FG, Thomas M. Study of antidiarrhoeal activity of four medicinal plants in castor oil induced diarrhea. Journal of Ethnopharmacology 2001; 76(1):73-76.

22. Kar DM, Maharana L, Rout SP. CNS activity of aerial parts of Hybanthus enneaspermus Mull. Pharmacologyonline 2010; 3:959-981.

23. Atanasov AG, Waltenberger B, Pferschy-Wenzig EM, et al Discovery and resupply of pharmacologically active plantderived natural products: A review. Biotechnology Advances 2015; 33(8):1582-1614.

24. Hossan MS, Jindal H, Maisha S, et al. Antibacterial effects of 18 medicinal plants used by the Khyang tribe in Bangladesh. Pharmaceutical Biology 2018; 56(1):201-208.

Manandhar S, Luitel S, Dahal RK. In vitro antimicrobial activity of some medicinal plants against human pathogenic bacteria. Journal of Tropical Medicine 2019; Article ID 1895340, 5pages.

25. Khatun MH, Nesa ML, Islam R, Ripa FA, Mamun A, Kadir S. Antidiabetic and anti-diarrheal effects of the methanolic extract of Phyllanthus reticulates leaves in mice. Asian Pacific Journal of Reproduction 2014; 3:121-127.

26. Naher S, Aziz MA, Akter MI, Rahman SMM, Sajon SR, Mazumder K. Anti-diarrheal activity and brine shrimp lethality bioassay of methanolic extract of Cordyline fruticosa (L.) A. Chev. Leaves. Clinical Phytoscience 2019; 5:15.

27. Rout SK, Kar DM. Sedative, anxiolytic and anticonvulsant effects of different extracts from the leaves of Ipomoea carnea in experimental animals. International Journal of Drug Development and Research 2013; 5(2):232-243. 